Howe, C. (2015). Latin America in the Anthropocene: Energy Transitions and Climate Change Mitigations. The Journal of Latin American and Caribbean Anthropology, 20(2), 231-241. http://doi.org/10.1111/jlca.12146

\title{
Latin America in the Anthropocene: Energy Transitions and Climate Change Mitigations
}

\author{
Cymene Howe \\ Rice University, Department of Anthropology
}

Energy creates both possibilities and liabilities. Plentiful, inexpensive energy has long been a cornerstone of modernist dreams of never-ending expansion. While this may be a fantasy, the truth - at least according to overwhelming scientific evidence - is that our use of fossil fuels has led to distressing global consequences. In May 2013, the U.S. National Oceanic and Atmospheric Administration reported that the average daily level of atmospheric carbon dioxide levels had exceeded 400 parts per million, a density of heat-trapping gases that has not existed for at least three million years, long before humans evolved (Gillis 2013). The Holocenic conditions in which we developed as a species have expired, and the Anthropocene, an epoch defined by the advent of urban-industrial society as a geological force, seems to have taken its place. Human landscape transformation now massively exceeds natural sediment production and ocean acidification and the destruction of biota are the new norm, meaning that evolution itself has been "forced into a new trajectory" (Davis 2010:31). The reality of increased global energy consumption and its concomitant climatological effect has meant that local practices are now universal concerns. In this special issue of the Journal of Latin American and Caribbean Anthropology each author works within this spirit of currency, recognizing that we-as social subjects, as a species, or as inhabitants of a planet shared with other biotic life - are living in a time of decisions that will echo for centuries to come. In this collection, we examine the complexity of renewable energy transitions in Latin America and we analyze the related processes of its twin (or perhaps its impetus): the policies and projects intended to address global climate change. While anthropological work on petroleum has been important to our better understanding of the social, economic, and environmental consequences of hydrocarbons (Behrends et al. 2011; Breglia 2013; Coron'1l 1997; McNeish and Logan 2012; Sawyer 2004), this volume maintains a critical focus on forms of renewable energy and climate mitigation efforts. Our understanding is that, first, "renewable" energy and [End Page 231] sustainability 
are categories that must remain bracketed (in the case of hydroelectric dams, for example) ${ }^{1}$ and second, that many renewable energy projects succumb to the habits of hydrocarbon extraction in their financing and production processes if not in their cumulative environmental consequences. The articles collected here are committed to engaging questions of extraction and generation, implementation policies and reactions to them, as well the cultural, social, and scientific intersections of energy, political power, and climatological warming. Ultimately, we ask how it is that the Anthropocene ${ }^{2}$ is being experienced, negotiated, and remapped in Latin America.

Latin America has a vast potential to generate clean electricity, produce sustainable fuels, and provide carbon sequestration. Historically, however, Latin American populations have not contributed large quantities of contaminative greenhouse gases to our collective atmosphere. Therefore, while the region could be a massive producer of sustainable power, the question remains: should it? Is it the responsibility of Latin American nation states to invest political and economic resources to remedy global environmental contamination? And, if energy production continues to prioritize destructive and displacing megaprojects, can governments, energy developers, and communities balance the needs of local populations against the development desires of neoliberalismo verde?

Latin America has long endured various forms of extraction: mineral, hydrocarbon, biotic, and human. While accounting for this history of expropriations, the articles featured here also attempt to invert this legacy by asking how energy transition and climate change policies might produce positive changes in the region both politically and socially. We ask if there are possibilities for greater equality, or ways to challenge ruling paradigms of neoliberal governance, in the overlapping processes of renewable energy generation and climate mitigation efforts. In addition to detailing the technological and social dynamics of hydroelectric power, wind power, biofuels, and relationships between petroleum production and climate protection, our discussions address ethical considerations, environmental justice, and human rights. They consider how local communities are responding to calls for global climate mitigation, how renewable energy developers are invoking the logics of climate change as they pursue their agendas, and how national governments are investing, financially and symbolically, in renewable energy forms. We reflect on how energy transitions and climate change policies are being experienced and articulated across Latin America, as well as how these processes coincide with imaginaries of fuel, power, and futurity.

\section{Energy, Extraction, and Climate Politics in Latin America}

Latin America and the Caribbean lead the world in the use of renewable sources of energy, particularly hydroelectricity and biofuels; however, there is much more [End Page 232] renewable potential on the horizon in the form of solar and wind, and in/on the ground in the form of geothermal, hydroelectric, and biomass, among others. Nicaragua has announced, for example, that they aim to have 95 percent renewable electricity by 2017, largely generated by privately sponsored wind parks, hydroelectric dams, and geothermal plants. Argentina has an ambitious solar initiative as part of a national strategy to generate electricity from renewable sources. Mexico has also committed to reduce greenhouse gas emissions by 50 percent by 2050 . Policies are, of course, fueled in part by fiscal interests; new investments in Latin American clean energy projects rose 127 percent from 2011 to 2012, reaching a total of \$4.6 billion. ${ }^{3}$ Increased energy production across Latin America has become a mandate, as demand across the region has more than doubled in the last 40 years (Tissot 2012:2), rising three percent over the 
past decade. Pipelines and grids that allow for transnational energy export have also become a source of local and national revenue. Rising energy expectations, grid extensions, and demands for low-cost fuel often rest on the assumption that access to energy portends economic growth and enhances quality of life, even if this is not necessarily accurate (Nader and Beckerman 2010). Aspirations for renewable energy development and increased production are not always realized and, at times, follow the familiar maneuvers of hydrocarbon exploitation. These include, as we see in the articles here, projects of massive scale and inadequate community consultation or consent. In response, both petropolitics and green capitalism are being challenged by sustainability movements and translocal claims for human and environmental rights across much of Latin America.

Latin America has a long and complicated history with energy resources, most of which has been defined by colonial and corporate forays that have resulted in both human and environmental degradation (Howe 2014). The discovery of Venezuela's Mene Grande oil field in the spring of 1914 was followed by decades of foreign capitalists hoping to unearth vast profits from the country's enormous petroleum reserves. Or, as Eduardo Galeano put it, "[i]t is the corporations, pencils on a terrestrial globe, that decide which zones will be exploited and which held in reserve, what price producers must get and what price consumers must pay" (Galeano 1997:159). The recent victory achieved by residents of the Ecuadorean Amazon in their lawsuit against Texaco Chevron — one of the largest financial judgments ever imposed for environmental contamination anywhere - demonstrates how the question of who "must pay" appears to be changing, at least to some extent (Sawyer 2004). Each of these cases exemplifies how channels of transnational capital and the petropolitics of extraction have produced immense wealth and, at the same time, endangered lives. So-called "traditional" extractivism - the securing of hydrocarbon and mineral resources, since colonial times (Bebbington 2009; Turner 1995) — has been paradigmatic in Latin America, although it has probably contributed relatively little by way of overall national development [End Page 233] (Gudynas 2009:187). New modes of energy extraction and climate mitigation policies ought to be tested against these legacies so that future energy developments do not simply repeat the errors of a petroleum-driven past.

While petropolitics have shown their debilities for decades, green capitalist models, or neoliberalismo verde - favoring private investment, institutional loans, and limited government management - has also faced challenges throughout Latin America. Bolivian President Evo Morales, for example, nationalized two electricity distribution facilities owned by Iberdrola, the world's leading producer of wind energy and one of the largest utility companies on the planet. International economic investments that purport to enhance "sustainable livelihoods" may be beneficial, both locally and globally, but they must also be understood against a backdrop of enduring economic and political interventions (Barnes et al. 2013:543). Just as colonial and corporate extractivism have benefitted affluent patrons and regions at the expense of others, so too can climate change adaptation and renewable energy initiatives operate as new axioms for resource exploitation in the name of clean development. The critical pivot for programs of renewable energy will depend on whether sustainable paradigms can be enacted in more equitable and rights-conscious ways than has previously been the case, especially as energy forms increasingly condition both national and transnational politics.

Recalibrating the ways in which energy is both produced and consumed has been a central component of Latin America's "leftward turn," the most famous being Hugo Chávez's redistribution of petrowealth in Venezuela. Argentina, Bolivia, and Ecuador, among others, have also attempted to thwart patterns of foreign extractivism by cultivating more localized forms of 
energy sovereignty. Under "progressive neo-extractivism," a larger share of resource profits are directed to local and national populations as neoleftist governments attempt to rewrite the logics of extractivism by providing social programs for their citizens. As Anthony Bebbington has put it, these are policies intent on "making the most from extraction" (2009:14). Progressive neoextractivism may allow state agents to play a more active role in the management of energic resources and the redistribution of benefits, but this continues to depend upon a matrix of international state and corporate interests that are integrated into these models as consumers, financiers, or development experts. Whether in service to renewable energy production or more responsible hydrocarbon redistribution, extractivism, by any name, is development that ultimately depends upon "the appropriation" and exploitation of ecological "resources" (Gudynas 2009:188). The potential for environmental damage and a reliance on international capital markets continue to define resource-based economic and social programs. These remain central concerns in debates about how harm can be reduced and redistributive justice enhanced in an era- and an area, such as Latin America - that is still largely steeped in neoliberal economic policies and development projects. [End Page 234]

Both state power and private development mechanisms are implicated in plans for renewability or a greener neoliberalism. As several of the articles included here suggest, neither of these forms should be taken as the presumed, singular, or correct standard for energy production or management. Instead, we are interested in understanding the dynamics at play among bureaucratic institutions, policy measures, economic development models, and the experiences of citizen subjects, who are often glossed as "consumers" or "partners" in energy and climate change discourses. How energy resources are secured and delivered, as Timothy Mitchell (2011) has demonstrated for the case of hydrocarbons, reverberates throughout contemporary forms of governance and power. Mitchell contends that democratic institutions themselves can be linked to the specific ways that coal, then oil, has been channeled: enhancing labor and political organizing opportunities for some while stifling them for others. Similarly, as the essays here demonstrate, there is a vast difference between "energy security"-state-based equations linking energy resources and military security—and "energy sovereignty," which prioritizes sustainable energy generation and human rights implicated in energy distribution and consumption. In this volume, our aim is to respond to larger ethical questions concerning energy and climate change mitigation policies by interrogating the role of states, financing entities, developers, scientists and others to demonstrate the articulation between energy sovereignty and parallel demands upon energy resources.

\section{The Analytics of Energy and Climate Change in Anthropology}

Latin America's contemporary conditions and its social histories provoke important questions about energy and climate mitigation that cross regional boundaries. The essays collected in this volume share a comparative regional perspective, but they also hold that anthropology's broader ethnological view is analytically significant, especially as climate and energy crises are increasingly understood to be global in scope. Given the ways in which energy continually shapes political and social life - in quotidian ways (from morning to night) and politically (from governance to economic growth) - it is surprising that the topic of energy has not been more central to anthropology. The last few years have seen a resurgence in the topic of energy, as researchers have tried to sort out the complex relationships between energy resources and their development, distribution, and social dynamics (e.g., Anthropological Quarterly 2014; Love and 
Garwood 2011; Mason and Stoilkova 2012;Nader 2010; Strauss et al. 2013; Wilhite 2005; Winther 2008). However, there has been a notable delay between the important work emerging now and earlier interpretations of energy in anthropology.

In the early 20th century, anthropologist Leslie White understood energy as the key to understanding all of human culture, and indeed all existence. As he wrote, [End Page 235] "we see, on all levels of reality, that phenomena lend themselves to description and interpretation in terms of energy" (1943:335). While there is no need to resuscitate White's evolutionary determinism, his fascination with energy resonates in the contemporary ways that energy occupies nearly every aspect of our quotidian existence. White's emphasis upon universality also finds a poignant echo in totalizing diagnoses of climate crisis and catastrophe. Climatological consequences, however, are not felt evenly everywhere, nor can climate blame be attributed to all human beings equally. From an ethnographic point of view, totalizing statements and universal prognoses lack subtlety, and are therefore apt to misrecognize key differences regarding energy utilization and its climatological outcomes. Attention to these distinctions is where a second generation of energy anthropologists has made important contributions.

Several decades after White's intervention, anthropology entered another stage of analysis concerning energy's force and impact. Environmental destruction and human endangerment caused by oil extraction and nuclear power production were focal points for anthropological work that sought to demonstrate the immediate consequences of energy production and extraction. Work on uranium mining, for instance (Johnston et al. 2007), stands as a clear example of how the policies and practices of nuclear energy generation combined to contaminate Navajo lands and cause severe health consequences. Focusing on specific case studies and (usually) negative impacts of energy production, scholars were able to demonstrate how local populations' rights were susceptible to injurious processes of energy development, particularly those with massive scale and duration. The potential for human and environmental exploitation deeply informed this second generation of anthropological inquiry. This dynamic continues to inform contemporary work on the social life of energy as well as the politics of climate change mitigation, as we see throughout this volume. How political power becomes channeled through energy production and consumption, and the ways in which climate remediations may enhance or inhibit local claims for sovereignty and rights must remain a central focus of energy studies. These dynamics not only illustrate how protests are mounted, projects halted, or concessions made, but they also show how deeply imbricated energy is in our social interactions and lifeways.

In much of the emerging work on energy and its environmental consequences, there is a focus on policy, statecraft, and the role of experts and scientists. These analytic attentions are indebted, at least in part, to Laura Nader's earlier work on energy and expertise. Nader's participation in a national dialogue convened by the U.S. National Academy of Sciences allowed her to be both part of the scientific conversation as well as an analyst of how scientific knowledge was used in politically charged decisions about energy production and systems of utilization. Nader underscored that one of the values of an anthropological perspective in this context was the discipline's extended time horizon - from long-term fieldwork in [End Page 236] specific locations to archaeological records showing the rise and fall of civilizations (Nader 2010:1). The historical depth of ethnographic approaches has been important for understanding how communities negotiate energy production, distribution, and consumption over time. Attending to these kinds of temporalities is perhaps doubly imperative now in an anthropocenic context in which both historical depth (of the particular) and extended horizons 
(of possible futures) are vital elements of both analytic and social possibilities. The compounding and intergenerational effects of energy utilization and its environmental impact make it difficult to ignore, as ethicist Stephen Gardiner has put it, "how nature becomes a vehicle through which injustice is visited on other people" (Gardiner 2011:43). To consider energic and climatological processes in historic depth and to chronicle the present with an eye to futurity, is, for many of us working in the anthropology of energy, an intellectual imperative that we cannot afford to ignore or delay.

The arrival of the Anthropocene may be an unprecedented event in human and geologic history, but its genesis relates to a much longer relationship between human beings and the/ir environment. These interactions, and philosophical inquiries into them, have been the source of speculation, written and oral, going back thousands of years. Although the anthropology of climate change has a recent place in this history, the discipline has engaged the role of climate, seasonality, weather, and environmental conditions for some time. Evans-Pritchard, for instance, was deeply interested in Nuer seasonality and its impact on cattle, resources, and social structure. Marcel Mauss's discussions of Eskimo seasonality took seasonal conditions, as well as the relationships between human and nonhuman populations as key indicators of larger social processes. Cultural ecology in the hands of Julian Steward was committed to demonstrating how social adaptation to environments led to different cultural outcomes. However, where early social thinkers were concerned with how ecological or seasonal factors had an impact on, conditioned, and transformed social and cultural life, these polarities have now been reversed. The original anthropological formulations of seasonality, weather, and climate conditions were concerned with their impact on human physiology and social life. In the present, it is human habits, energic practices, and social life that are dramatically changing climate, weather, and seasonality.

Over the last decade, anthropological attention to scientific discourses and the outcomes of climate change have grown substantially (Barnes et al. 2013; Cambridge Anthropology 2013; Crate and Nuttall 2009; Roncoli et al. 2009; Strauss and Orlove 2003).Hallie Eakin's (2006) work, for example, provides a close ethnographic reading of how rural farmers in Mexico negotiate and manage social and economic risk in the face of climatological vulnerability. Farmers and others with subsistence practices that depend closely upon natural systems are able to carefully narrate past and present experiences of weather and climate. They therefore become [End Page 237] repositories of knowledge and strategists of resiliency for both rural livelihoods and biotic preservation efforts. Although it is only recently that anthropological studies have specifically focused on the intersection of indigenous knowledge and experiences of climate change, folk epistemologies of climate, and its importance, are proving important for anthropological work; these also follow from a longer anthropological tradition that has centered on indigenous environmental knowledge from ethnoscience to political ecology. Rhoades et al. (2008) describe, for example, how the receding snowcap on the summit of "Mama Cotacachi" volcano in highland Ecuador is seen locally as a loss of the volcano's "youth and beauty." While personifications of geologic entities is not a new phenomenon, shifts in collective understandings resulting from climate change do invite questions about temporal perceptions of landscapes, biotic life, and human engagements with them (Ingold 2004). If terrestrial and oceanic forms - especially those that have been understood as unchanging and "timeless" — are in fact changing and their time marked, how does this articulate perceptions of human vulnerability? These phenomena open new spaces for anthropological work in which the perceptual subtleties of local populations can be juxtaposed against longer temporal and spatial scales. 
To illustrate the differences between local and global experiences and interpretations of climate change, attention has also been focused on climate change science as an intellectual field. Building from studies of meteorology, Myanna Lahsen (2005) has shown, for example, how scientific authority is constructed in climate research and policy. We find that climate scientists have profound personal investments in their models, although the scientific process itself is often fragmented and susceptible to extremely competitive funding prospects. Anthropologists have also studied the work of the Intergovernmental Panel on Climate Change (IPCC), the current arbiter of climate change policy, as well as the politics and information practices of global warming denial. Ethnographic insights and historical perspectives have provided important evaluations of how populations and communities perceive climate change as well as the social institutions that manage its consequences. In the articles collected here, attention is paid to both the science and the politics surrounding climate change mitigation as well as to their inherent logics. Rather than focusing exclusively upon how climate change is perceived and felt, we follow in the tradition of political anthropology - as well as anthropological work on experts, disaster, environmental management, and science and technology studies - to engage critically with the policies, projects, and knowledge practices surrounding potential solutions and accommodations to climate change. [End Page 238]

\section{Futurities}

Energy and climate change speak to fundamental tensions in the anthropological imagination, challenging us to balance interactions between broad social processes and experiential, quotidian life in situated contexts. If solutions to global climate change are on the horizon-whether in terms of "accommodations," international protocols, or radical reconstructions of consumption practices - this will require analyzing projects and policies that are touted as planet-preserving (the universal appeal) as well as those projected to benefit local populations (the particular appeal). The Anthropocene demands attention to both universal and particular contingencies. The case studies from Latin America that are collected here provide ethnographic depth and detail, but they also ask, implicitly, what anthropology can bring to larger, trans-regional discussions of climate change and energy transitions. Beyond our ability to detail local responses to specific renewable energy projects or climate change policies, and beyond our ability to express the values and cultural contingencies at work in these (often fraught) political and social domains, we believe that anthropologically informed analysis has a capacity, and even a responsibility, to provide parallels, points of contrast, and polydimensional interpretations of energy transition and climate change mitigation. Anthropologies of energy and climate change have shown, and will continue to show, the conflicted politics of energy and global warming. However, we also know that anthropology has a mandate to understand human relatedness and sociality. If, as postcolonial theorist Dipesh Chakrabarty (2009) has suggested, our anthropocenic conditions require not simply new ways to view history, but new imaginaries of human social cohesion, or "species thinking," then anthropology's ability to understand how we innovate collective sensibilities and commitments will be an important way to think through possible futurities. 


\section{Notes}

${ }^{1}$ Hydroelectric dams' status as a form of "clean" energy production has long been challenged. Silt and organic materials in the reservoirs' depths produce toxic and climate-altering methane gas, among other environmental damage. Added to their environmental liabilities are the human displacements for which dams have become so infamous.

${ }^{2}$ Anthropocene remains a contested term in the social sciences; neither is it fully qualified by geologists. See, for example, Steffen, Crutzen and McNeill 2007.

${ }^{3}$ This total figure does not include Brazil. InMexico, total new financial investment in clean energy for 2012 was $\$ 1.9$ billion, up 595 percent from 2011 figures. Chile had $\$ 1$ billion, up 313 percent from the previous year, and Uruguay reported total new investments of $\$ 105$ million, up 285 percent from 2011. Peru's total investments were $\$ 643$ million, or an increase of 176 percent from the previous year (American Council on Renewable Energy, April 24, 2013).

\section{References Cited}

American Council on Renewable Energy (ACORE). (2013) Clean Energy Investments in Latin America Total \$9.7 Billion in 2012 Four Countries Saw Triple-Digit Investment Growth. Bloomberg New Energy Finance. April 24, 2013. http://www.acore.org/newsmedia/press-releases/3318-clean-energy-investments-in-latin-americatotal-9-7-billion-in2012, accessed June 5, 2013.

Anthropological Quarterly. (2014) Special Issue: Energopower and Biopower in Transition. Guest Editor: Dominic Boyer 87(2).

Barnes, Jessica, Michael Dove, Myanna Lahsen, Andrew Mathews, Pamela McElwee, Roderick McIntosh, Frances Moore, Jessica O’Reilly, Ben Orlove, Rajindra Puri, Harvey Weiss and Karina Yager (2013) Contribution of Anthropology to the Study of Climate Change. Nature Climate Change 3(June):541-544.

Bebbington, Anthony. (2009) The New Extraction: Rewriting the Political Ecology of the Andes? NACLA Report on the Americas (September/October):12-20.

Behrends, Andrea, Stephen Reyna, and Guenther Schlee, eds. (2011) Crude Domination: The Anthropology of Oil. New York: Berghahn.

Breglia, Lisa. (2013) Living with Oil: Promises, Peaks and Declines on Mexico's Gulf Coast. Austin: University of Texas Press.

Cambridge Anthropology. (2013) Special Section: Climate Histories and Environmental Change: Evidence and its Interpretation. Guest Editor: David Sneath 31(1).

Chakrabarty, Dipesh. (2009) The Climate of History: Four Theses. Critical Inquiry 35(Winter):197-221.

Coroníl, Fernando. (1997) The Magical State: Nature, Money, and Modernity in Venezuela. Chicago: University of Chicago Press.

Crate, Susan, and Mark Nuttall, eds. (2009) Anthropology and Climate Change. Walnut Creek, CA: Left Coast Press.

Davis, Mike. (2010)Who Will Build the Ark? New Left Review 61(January/February):29-46.

Eakin, Hallie. (2006) Weathering Risk in Rural Mexico: Climatic, Institutional, and Economic Change. Tucson: University of Arizona Press. 
Galeano, Eduardo. (1997) Open Veins of Latin America: Five Centuries of the Pillage of a Continent. New York: Monthly Review Press.

Gardiner, Stephen. (2011) A Perfect Moral Storm: The Ethical Tragedy of Climate Change. Oxford: Oxford University Press.

Gillis, Justin. (2013) Heat-Trapping Gas Passes Milestone, Raising Fears. New York Times, May 10. http:// www.nytimes.com/2013/05/11/science/earth/carbon-dioxide-level-passeslong-feared-milestone.html?pagewanted=all\& $\mathrm{r}=0$, accessed June 4, 2013.

Gudynas, Eduardo. (2009) Diez Tesis Urgentes Sobre El Nuevo Extractivismo: Contextos y Demandas Bajo el Progresismo. En Extractivismo, Política y Sociedad CAAP (Centro Andino de Acción Popular) y CLAES (Centro Latino Americano de Ecología Social) Quito, Ecuador. Noviembre 2009.

Howe, Cymene. (2014) Anthropocenic Ecoauthority: The Winds of Oaxaca. Anthropological Quarterly 87(2):381-404.

Hulme, Mike. (2011) Reducing the Future to Climate: A Story of Climate Determinism and Reductionism. Osiris 26:245-266.

Ingold, Tim. (2004) Culture on the Ground: The World Perceived through the Feet. Journal of Material Culture 9(3):315-340.

Johnston, Barbara Rose, Susan E. Dawson, and Gary E. Madsen. (2007) Uranium Mining and Milling: Navajo Experiences in the American Southwest. In Indians and Energy. Sherry Smith, and Brian Frehner, eds. Pp. 97-116. Santa Fe: SAR Press.

Lahsen, Myanna. (2005) Seductive Simulations: Uncertainty Distribution around Climate Models. Social Studies of Science 35:895-922.

Love, Thomas, and Anna Garwood. (2011) Wind, Sun and Water: Complexities of Alternative Energy Development in Rural Northern Peru. Rural Society 20:294-307.

Mason, Arthur, andMaria Stoilkova. (2012) Corporeality of Consultant Expertise in Arctic Natural Gas Development. Journal of Northern Studies 6(2):83-96.

McNeish, John-Andrew, and Owen Logan, eds. (2012) Flammable Societies: Studies on the Socioeconomics of Oil and Gas. London: Pluto Press.

Mitchell, Timothy. (2011) Carbon Democracy: Political Power in the Age of Oil. New York: Verso.

Nader, Laura, ed. (2010) The Energy Reader. Malden: Wiley-Blackwell.

Nader, Laura, and Stephen Beckerman. (2010) Energy as it Relates to the Quality and Style of Life. In The Energy Reader. Laura Nader, ed. Pp. 219-245. New York: Wiley-Blackwell.

Rhoades, Robert, Xavier Zapata, and Jenny Aragundy. (2008) Mama Cotacachi: Local Perceptions and Societal Implications of Climate Change, Glacier Retreat, and Water Availability. In Darkening Peaks: Mountain Glacier Retreat in Social and Biological Contexts. Ben Orlove, Ellen Wiegandt, Brian H. Luckman, eds. Pp. 218-27. Berkeley: University of California Press.

Roncoli, Carla, Todd Crane, and Ben Orlove. (2009) Fielding Climate Change in Cultural Anthropology. In Anthropology and Climate Change. Susan Crate, and Mark Nuttall, eds. Pp. 87-115. Walnut Creek, CA: Left Coast Press.

Sawyer, Suzana. (2004) Crude Chronicles: Indigenous Politics, Multinational Oil, and Neoliberalism in Ecuador. Durham, NC: Duke University Press.

Steffan, Will, Paul J. Crutzen, and John R. McNeill. (2007) The Anthropocene: Are Humans Now Overwhelming the Great Forces of Nature? Ambio 36(8):614-621.

Strauss, Sarah, Thomas Love, and Stephanie Rupp, eds. (2013) Cultures of Energy. Walnut 
Creek, CA: Left Coast Press.

Strauss, Sarah, and Ben Orlove, eds. (2003)Weather, Climate, Culture. Oxford: Berg.

Tissot, Roger. (2012) Latin America's Energy Future. Interamerican Dialogue. Working Paper. http://www.thedialogue.org/PublicationFiles/Tissotpaperweb.pdf, accessed June 12, 2013.

Turner, Terence. (1995) An Indigenous People's Struggle for Socially Equitable and Ecologically Sustainable Production: The Kayapo Revolt Against Extractivism. Journal of Latin American and Caribbean Anthropology 1(1):98-121.

White, Leslie. (1943) Energy and the Evolution of Culture. American Anthropologist 45(3):335356.

Wilhite, Harold. (2005)Why Energy Needs Anthropology. Anthropology Today 21(3):1-3.

Winther, Tanja. (2008) The Impact of Electricity: Development, Desires and Dilemmas. Oxford:

Berg. 